\title{
INTEGRATED ASSET AND LIABILITY PORTFOLIO AS INSTRUMENT OF LIQUIDITY MANAGEMENT IN THE COMMERCIAL BANK
}

\author{
Aleksandras Vytautas Rutkauskas', Jelena Stankeviciene ${ }^{2}$ \\ Vilnius Gediminas Technical University, Saulètekio al. 11, LT-10223 Vilnius, Lithuania \\ E-mail: 1ar@vv.vtu.lt; ${ }^{2} e l e n a s t @ v v . v t u . l t$
}

Received 1210 2005; accepted 27022006

\begin{abstract}
Liquidity, or the ability to fund increases in assets and meet obligations as they come due, is crucial to the ongoing viability of any banking organization. Therefore, managing liquidity is among the most important activities conducted by banks. Liquidity management model proposed by the authors can reduce the probability of serious problems. Indeed, the importance of liquidity transcends the individual bank, since a liquidity shortfall at a single institution can have system-wide repercussions. For this reason, the analysis of liquidity requires bank management not only to measure the liquidity position of the bank on an ongoing basis but also to examine how funding requirements are likely to evolve under various scenarios, including adverse conditions.

The authors have focused on developing a greater understanding of the way in which banks can manage their liquidity using a broad potential of integrated asset and liability portfolio. As instrument for the solution of the assessed problem the integrated total commercial bank asset and liability structure formation and management when useful occurrence of integrated structure and every outcome is followed with some guarantee to occur was chosen. An academic example is shown as an illustration for ideas analyzed.

The formality and sophistication of the process used to manage liquidity depends on the size and sophistication of the bank, as well as the nature and complexity of its activities. The principles focused in the paper have broad applicability to all banks. In particular, good management information systems, analysis of net funding requirements under alternative scenarios, diversification of funding sources, and contingency planning are crucial elements of strong liquidity management at a bank of any size or scope of operations.
\end{abstract}

Keywords: liquidity management, integrated assets and liabilities portfolio, risk and uncertainty

\section{Introduction}

Liquidity, or the ability to fund increases in assets and meet obligations as they come due, is crucial to the ongoing viability of any banking organization. Therefore, managing liquidity is among the most important activities conducted by banks. Integrated asset and liability portfolio management can reduce the probability of serious liquidity problems. Commercial bank asset and liability management can be defined as the simultaneous planning of all asset and liability positions under consideration of the different bank management objectives and legal, managerial and market constraints, for the purpose of enhancing the value of the bank, providing liquidity and mitigating risk. Indeed, the importance of liquidity transcends the individual bank, since a liquidity shortfall at a single institution can have system-wide repercussions. For this reason, the analysis of liquidity requires bank management not only to measure the liquidity position of the bank on an ongoing basis but also to examine how funding requirements are likely to evolve under various scenarios, including adverse conditions.

In this work on the application of integrated asset and liability portfolio, the authors have focused on developing a greater understanding of the way in which banks manage their liquidity by using the integrated asset and liability portfolio. Asset and liability management deals with the efficient management of sources and uses of bank funds concentrating on profitability, liquidity, capital adequacy and risk factors in a dynamic and competitive economic environment (Oguzcoy C. B., Güven S., 1997; Kosmidou K., and Zopounidis C., 2001). The banking business has recently become more sophisticated due to rapid technological developments, expansion of economies, diversity in bank operations, and increased competition and/or relationship between financial institutions. In the finance world, future unpredictability is termed volatility: volatility of asset prices and uncertain liabilities clearly affects financial plans. In general such uncertainties lead to possible financial loss or in 
other words financial risk. Especially in unstable economic environments, success of a bank depends on the quality of its asset and liability management. Banks are in the business of management of conflicting objectives (such as maximization of profit and minimization of risk).

This paper sets out several principles that highlight the key elements of integrated asset and liability portfolio for effective liquidity management.

There are many studies that have been developed concerning the bank asset liability management techniques.

\subsection{Previous research}

Looking to the past, we find the first mathematical models in the field of bank management. Asset and liability management models can be deterministic or stochastic. The deterministic linear programming model of Chambers and Charnes (1961) is the pioneer on asset and liability management. Their model corresponds to the problem of determining an optimal portfolio for an individual bank over several time periods in accordance with requirements laid down by bank examiners which are interpreted as defining limits within which the level of risk associated with the return on the portfolio is an acceptable one. Cohen and Hammer (1967) Komar (1971) Lifson and Blackman (1973) are successful applications of Chambers and Charnes model. Other successful linear programming applications are Eielitz and Loeffler (1979) Crane et al. (1977) and Robertson (1972). Fortson and Dince (1977) Eatman and Sealey (1979) Tayi and Leonard (1988) and Giokas and Vassiloglou (1991) use multi-objective decision making techniques to handle conflicting objectives. Eatman and Sealey (1979) developed a multiobjective linear programming model for commercial bank balance sheet management considering profitability and solvency objectives subject to policy and managerial constraints. Giokas and Vassiloglou (1991) developed a goal-programming model for bank asset and liability management. They supported the idea that apart from attempting to maximize revenues, management tries to minimize risks involved in the allocation of the bank's capital, as well as to fulfill other goals of the bank, such as retaining its market share, increasing the size of its deposits and loans, etc. Conventional linear programming is unable to deal with this kind of problem, as it can only handle a single goal in the objective function. Goal programming is the most widely used approach that solves large scale multicriteria decision making problems.
Apart from the deterministic models, several stochastic models have been proposed since the 1970s. The stochastic models, in their majority, originate from the portfolio selection theory of Markowitz (1959) and they are known as static mean-variance methods. Pyle (1971) and Brodt (1978) adapted Markowitz's theory and presented an efficient dynamic balance sheet management plan that considers only the risk of the portfolio and not other possible uncertainties or maximizes profits for a given amount of risk over a multi-period planning horizon respectively.

Oguzcoy C. B., Güven S. (1997) categorized stochastic asset and liability management models into 8 main approaches.

The first approach is simulation models. Derwa (1973) Robinson (1973) and Grubmann (1987) report successful implementations of simulation models developed for various financial institutions. Although bank managers can more readily understand these models, their practical usage is limited as they can only handle a small number of alternatives.

The second approach of stochastic modeling originates from the theory of Markowitz (1959) of portfolio selection where "risk" is measured by variance in a single period planning horizon. Pyle (1971) applied Markowitz's theory in his model where a bank chooses the level of assets and liabilities that it aims to hold throughout the period. However, his model lacks a crucial aspect of bank management: asset-liability balance. Brodt (1978) adapted Markowitzs theory and presented an efficient dynamic balance sheet management plan that maximizes profits for a given amount of risk over a multiperiod planning horizon.

The third approach to stochastic modeling is chance constrained programming initially developed by Charnes and Thore (1966) and Charnes and Littlechild (1968). Pogue and Bussard (1972) have formulated a 12-period chance constrained model in which the only uncertain quantity is the future cash requirement. The major weakness of chance constrained programming is that it does not allow incorporation of differential penalty between a small and a large amount of violation in a constraint.

The fourth approach is the sequential decision theoretic approach, which is initially proposed by Wolf (1969). He proposed the sequential decision theoretic approach that employs sequential decision analysis to find an optimal solution through the use of implicit enumeration. Bradley and Crane (1972) have developed a bond portfolio management model using this approach. The most important disadvantage of the sequential decision theoretic approach is that all 
portfolio strategies should be enumerated and considered to obtain optimal solution.

The fifth approach is dynamic programming. Eppen and Fama (1971) modeled the three asset problem by using this approach. Even though these models successfully handle the dynamic and uncertain aspect of bank balance sheet management, they are not widely used due to computational difficulties when many assets and liabilities arc included. For a survey on bank applications, see Cohen et al., (1981).

The sixth approach is stochastic linear programming with simple resource in which each realization of the random variable is handled by constraint. The difficulty of conceiving the structure and the philosophy of the model, and also computer incapabilities, constituted a barrier in utilizing this approach in 1960s and 1970s. However, with the surge of computer industry, larger stochastic linear simple recourse models have been developed and solved either by using specialized algorithms to be faster, or by the existing linear programming solvers to be more comprehensible. Cohen and Thore (1970) Booth (1972) and Crane (1971) utilized this approach with a limited number of possible outcomes and time periods. Kallberg et al. (1982) have formulated a firm's short term financial planning problem as an stochastic linear programming with simple resource model where forecasted cash requirements are discrete random variables. Kusy and Ziemba (1986) employed a multi-period stochastic linear program with simple recourse to model the management of assets and liabilities in banking while maintaining computational feasibility. Their results indicate that the proposed ALM model is theoretically and operationally superior to a corresponding deterministic linear programming model and that the computational effort required for its implementation is comparable to that of the deterministic model. Another application of the multistage stochastic programming is the RussellYasuda Kasai model (Carino et al., 1994), which aims at maximizing the long term wealth of the firm while producing high income returns.

The seventh approach is dynamic generalized networks. Mulvey and Vladimirou (1989) Mulvey and Vladimirou (1992) exploit network structure in financial planning problems. Mulvey and Vladimirou (1992) used dynamic generalized network programs for financial planning problems under uncertainty and they developed a model in the framework of multiscenario generalized network that captures essential features of various discrete time financial decision problems. Finally, Mulvey and Ziemba (1998) present a more detailed overview of various asset and liability modeling techniques, including models for individuals and financial institutions such as banks and insurance companies.

The eighth approach is stochastic dedication model. These models have fixed income focus (Hiller and Eckstein, 1993).

Over the years, many models have been developed in the area of financial analysis and financial planning techniques. Kvanli (1980), Lee and Lerro (1973), Lee and Chesser (1980), Baston (1989), Sharma et al. (1995), among others have applied goal programming to investment planning. Booth et al. (1989), Giokas and Vassiloglou (1991), Seshadri et al. (1999) presented bank models using goal programming. These studies focus on the areas of banking and financial institutions and they use data from the bank financial statements.

The purpose of this paper is to present integrated assets and liabilities portfolio selection and management technique, which combines multiple criteria such as portfolio efficiency possibilities, risk of feasible value, guarantee of each possibility and the utility of a subject to determine the asset and liability structure of a commercial bank. The objectives used are based on liquidity, solvency and average yield of assets and liabilities. There are some conceptions quite uncommon in financial literature, which, however, are necessary needed in order to analyze reliability of expected results using methods mentioned in the article. One of those conceptions is isoguarantee, which is a line joining effectiveness (profit, profitability, incomes etc) indicators of the same guarantee in the possibilities - risk plane. Using ideas and techniques of Markowitz or modern portfolio and adequate with stochasticity of profit possibilities portfolio, integrated assets and liabilities portfolio is being offered, which helps to put in order the possibilities of analyzed process or subject expansion according to its levels of guaranties. Although the methods of analytic solution search are sometimes used in the analysis of cases, still the main method for analyzing complicated cases remains imitative technologies that can be understood as an interaction of computer counting and imitative modeling. Obtained results are shown in the geometric form. It is also necessary to admit that computer resources sometimes were not sufficient to present continuous processes in visually adequate discrete manner. To analyze extremely complicated situations huge resources of computer power and velocity are needed, but taking into account the fact that innovations outrun demand in this area, imitation technologies should be recognized as the most perspective mean of analysis 
of complicated quantitative cases helping to solve any analytical problem successfully.

The model structure proposed in the paper is particularly well suited to solve the ALM decision problem in evolving economies where shareholder value maximization is often stated across a multiple goal hierarchy. The result of solving the multi-criteria decision-making in ALM problem provided significant evidence that the method is viable for efficient ALM portfolio management under uncertainty economics.

\section{Integrated assets and liabilities portfolio formation and management}

This part of the article discusses the conception and techniques of integrated assets and liabilities portfolio management (IALPM) development problems as intersection of problems arising in development of new management perspective - integrated assetliability management (IALM) perspective and in development of integrated assets and liabilities portfolio (IALP) or investment portfolio adequate for stochasticity of investment profit possibilities.

The predominant organization management perspective that in manufacturing and trading entities was titled as systemic and as functional in finance called for an organization to be structured into line of functional units the decisions (management) of which are coordinated by a corporate plan based on a forecasts of macroeconomics environmental and individual indicators (Holmer M., 2001). It is very important to emphasize that the forecasts were not treated as sets of possibilities i.e. possible outcomes with its probabilities and moreover behavioural decisions were not oriented to reliability management (Spronk J., 1997; Rutkauskas A. V., 2002).

In the year 1970 John Galbraight named the last of XX century as an age of risk and uncertainty. The beginning of the XXI century also corresponds with this denomination. Among financial intermediaries this perspective was nominated as integrated asset-liability management (IALM) perspective. This perspective call for an organization to be structured into integrated units that include all the functional activity related to a line of business and call for business units to make decisions using risk-adjusted or hedged profitability. IALM is based on computerised decision models "that represent both the assets and liabilities associated with the business line, characterize the uncertainty of the future environment, and produce strategies for structuring the assets and liabilities of business line in ways that are profitable across a range of alternative future environments" (Holmer M. R., 2001). Because of complex volatility of future there is no alternative to IALM for financial intermediaries.

\subsection{IALM perspective: implementation results, challenges and problems}

The analysis of development of IALM perspective would testify the premises that, first, an evolution of management perspectives is an innovative management response to business problems and, second, the individual success of new management conception must be supported by an adequate technique. Really very often new management perspective evolves through the piecemeal implementation of new management techniques introduced to solve concrete problems arising under the older management perspective.

The subject of the process to investigate in the paper will be financial intermediaries as well as personal finance where IALM already has gained its right to be used conceptually and practically. Often is supposed that management for financial intermediary is nothing more than definition of correct structure of assets and liabilities. It seems to be the truth if one could define this structure under stochastical behaviour of main assets' and liabilities' properties.

Financial intermediaries sell their liabilities, which become assets for savers or other intermediaries. A liability's scheduled cash flow ought be seen as contingent in the sense that it depends on the occurrence of certain future events. Liabilities with contingent cash flows are inherently risky and buyer will pay for an intermediary's liability taking into account risk of the cash flows.

Financial intermediaries usually use the proceeds of the liability's sale plus equity capital to buy assets, which are the liabilities of investors or other intermediaries. The cash flow of these assets are contingent and are used to pay the liability's scheduled cash flow. Any asset cash flow remaining after the payment of the liability's cash flow is profit for the financial intermediary. Since most financial intermediaries issue liabilities with contingent cash flow schedules the future profitability of the intermediary is quite uncertain. That's why the basic management objective for intermediary is formulated as "to sell liabilities and to buy assets in a way that the net cash flow or profit is both substantial relative to equity and consistent across the range of contingent events that effect future asset and liability cash flow (Holmer M. R., 2001).

Thus stochasticity is a characteristic feature for intermediary's profitability as well as for the income of 
assets and for expenditure of liabilities. However, the nature of the stochasticity is different in both cases. And indeed, if assumption the type of variability of assets profitability immanent is the tendency: the higher the expected value of profit the higher is the variance (Kouwenberg R., 2001; Rutkauskas A. V., Stankeviciene J., 2003).

For the tendency of liability's expenditure (negative cash flow), the concept that higher guaranteed loan require higher expenditure and vice versa seems could be correct. Then the differences in the tendency of relations between cash flow variance (s) and expectation (EXP) of assets and liabilities are presented in fig 1.

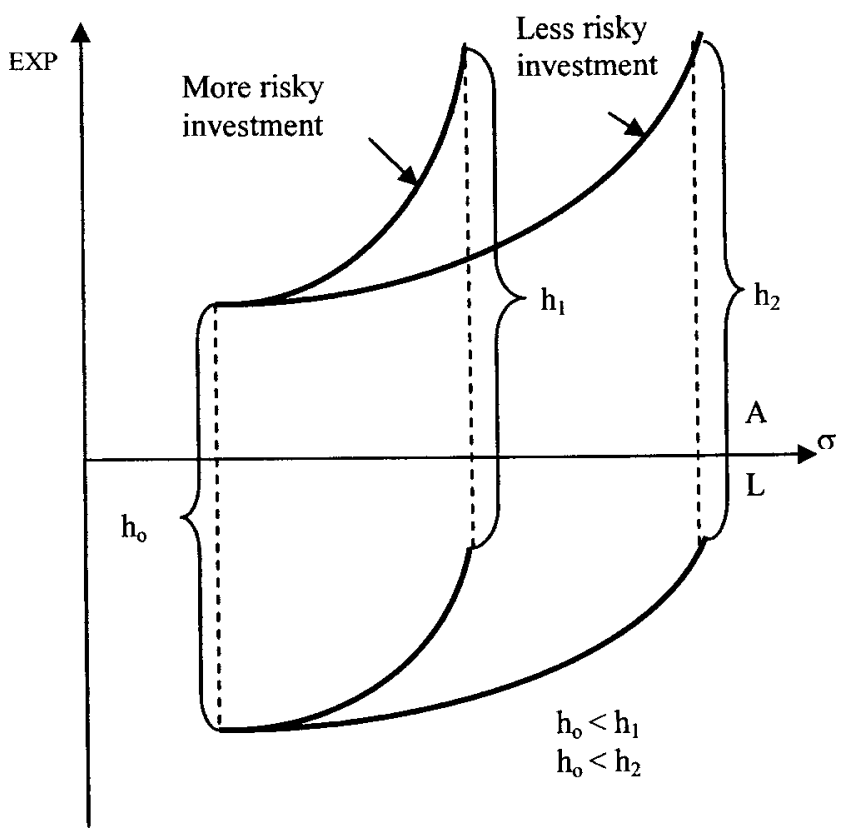

Fig 1. The differences in the tendency of relation between cash flow variance $(\sigma)$ and expected value $(\mathrm{EXP})$ for assets (semi plane A) and liabilities (semi plane L)

Regardless of conceptual sophisticate about the character of the cash flow i.e. about stochasticity of its nature positive cash flow from assets and negative - for expenses on liabilities altogether must comply with some request:

- The cash flow from the assets must be sufficient to pay the scheduled cash flow and taxes and difference between positive cash flow and negative cash flow and taxes must be sufficient for expected profit, also is treated as stochastical;

- Positive and negative cash flow must be interbalanced in every time interval.

Taking into account the above mentioned requirements and keeping in mind the stochastical nature of the cash flow it becomes obvious how complicated IALM techniques are needed. At that time every one can understand the importance of integrated assets and liabilities portfolio (IALP) to develop IALM for realization strategic goals: intermediary value maximization at the chosen time or other purpose. Certainly it is necessary to observe that presumption about stochasticity of cash flows bear the analogous presumption about stochasticity of intermediary's value. In this case the adequate concept and technique are needed for value management.

\subsection{The Main Equations and Constrains of the IALP}

Integrated asset and liability management system (IALMS) has its development and implementation for large financial institutions: commercial banks (Giokas D., 1991; Oguzcoy C. B., 1997), insurance companies (Carino D. R., 2001; Dert C., 2001; Merton R. C., 2001), etc. as well as for individual finance (Berger A. J., 2001).

This paragraph describes IALP as one chain of IALMS when it is used for strategic planning. We present the core of IALP's principle models system that could be used for financial management of intermediaries as well as for management of personal finance. The IALP helps to reinforce IALMS as strategic decision-making system. The main decision points over which IALP is integrated into IALMS are: where and how much to invest where and how much to borrow how to use leverage, how to maximize corporation or individual wealth at each stage, how to make adequate decision under the risk and uncertainty.

On the other hand, IALP is used for financial forecasting system (FFS) when the main financial statements: balance sheet, income statement, cash flow statement etc. are being generated (Rutkauskas A.V., 2000). Thus IALP could be helpful to coordinate IALM and FFS. Because IALP techniques are based entirely on stochastic modelling the principles of integrated risk management (IRM) could be implemented into IALMS. So IALP could be helpful to overcome uncertainty and complexity of many financial management problems.

Fig 2 represents the mechanic IALP and FFS, IRM and IALMS operation model, where IALP works as a bearing, which puts together forecasting and planning, risk and uncertainty, assets and liabilities and guaranties dynamics of financial subject.

The distinctiveness of IALP is its conformity with entirely stochastic system i.e. the system where the set 


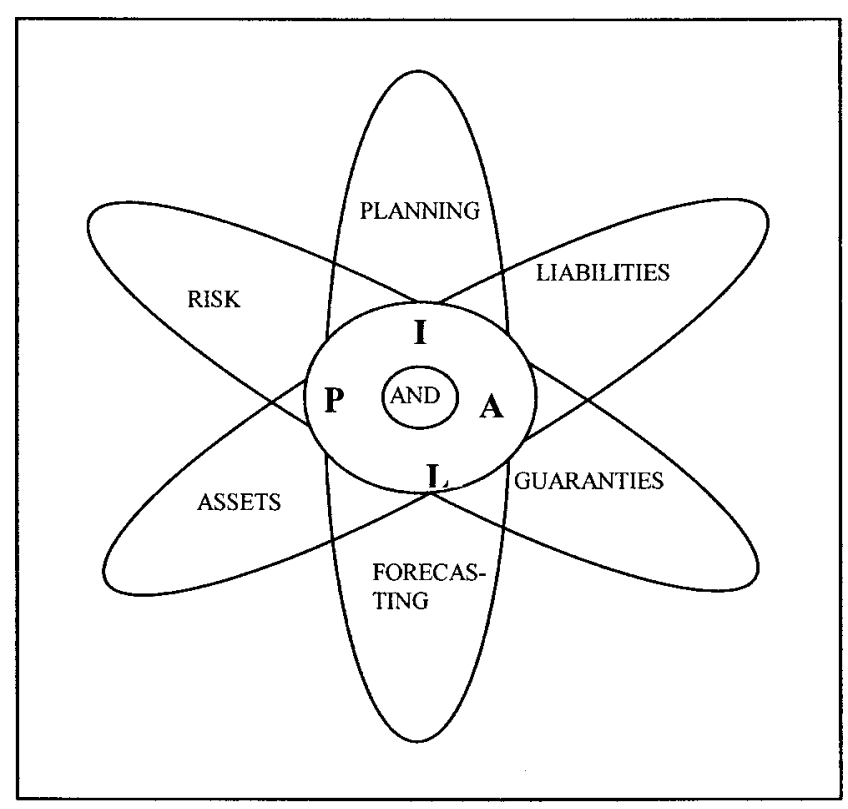

Fig 2. Mechanic IALP and FFS, IRM and IALMS operation model, where IALP works as a bearing, which puts together forecasting and planning, risk and uncertainty, assets and liabilities and guaranties dynamics of financial subject

of possibilities and the guaranties of these possibilities are regarded. In order to understand easier and for practice of implementation IALMS, FFS and IRM as dynamic instruments are used in the discrete form. So the IALP is also presented in discrete form as mathematical model where the time period $T$ also is divided by time moments: $t_{0}, t_{1}, \ldots . t_{n}$ into static intervals or stages $\left[t_{0}, t_{1}\right),\left[t_{1}, t_{2}\right), \ldots\left[t_{n-1}, t_{n}\right]$.

For convenience of exposition we suppose that the stage coincide with one-year period. The IALP switches on at start of each forecasting (planning) stage rendering changes to the asset and liability position, evaluating the results over the coming stage. Rebalancing assets and liabilities at times between reviewed points is not allowed. The mechanism of rebalancing depends on planning strategy is that stageby-stage strategy or we have an integrated by stages (over time) strategy. In the case we use the stage-bystage strategy. This situation simplifies exposition of portfolio techniques.

In the case we will present IALP as decision instrument on separate of all time period $\mathrm{T}$ though the behaviour of the managed system reacts on the issue of this decision and, vice versa, the objectives of the system cause the objectives and constraints of decision on separate stage. Different behaviour of the system means different changes in balance sheet, different incomes, and cash flow etc. statement results.

In our turn we will present only core changes that happen throughout one stage as static ring of all chain: changes in wealth, structure of asset and liability as well as changes in microenvironment (price, risk etc.).

We will define the relevant sets, accounting and decision variables, inputs, identities and governing equations for the IALP. However, before doing so we should note that for analytical convenience change in amount of every asset and liability will be treated as consisting of two non-intersecting components. First component appears as a result of rebalancing of already existing amount of assets and liabilities. The total amount of asset and liability doesn't change in this component. The second component is an increasement in every kind of asset and liability as a result of increase of total amount. Consequently those components are called: first - changes as result of rebalancing, second - newly introduced growth.

Let us define the following sets: $t_{1}, t_{2}, t_{n}$-discrete times at which the IALP will be rebalanced.

$T$ - time horizon (period) consisting of $\mathrm{n}:\left[t_{\mathrm{o}}, t_{1}\right),\left[t_{1}\right.$, $\left.t_{2}\right), \ldots\left[t_{n-1}, t_{k}\right]$ intervals, $t_{k}=T$. Further time moment $(t+1)$ will be identified with $t_{k+1}$ if $t=t_{k}$.

$i$ - asset categories, $i=1,2, \ldots n ; n$ - number of assets.

$j$ - liability categories, $j=1,2, \ldots m ; m$ - number of liabilities.

$a_{t}^{i}-$ amount of $i$ assets (in money) at time $t ; t=t_{1}$, $t_{2}, t_{n}$.

$l_{t}^{j}-$ amount of $j$ liability at time $t$.

Define the following decision and accounting variables:

$I_{t}^{a_{i}}$ - growth index of $i$ asset in result of rebalancing at the moment $t$.

$I_{t}^{a_{i}}=\left(1+\lambda_{t}^{a_{i}}\right)$, where $\lambda_{t}^{a_{i}}-$ change rate of $i$ asset at the moment $t$.

$I_{t}^{l_{j}}$ - growth index of $j$ liability in result of rebalancing at the moment $t$.

$I_{t}^{l_{j}}=\left(1+\lambda_{t}^{l_{j}}\right)$, where $\lambda_{t}^{l_{j}}-$ change rate of $j$ liability at the moment $t$.

$\lambda_{t, n}^{a_{i}}$ - fraction of assets newly invested in asset category $i$ at time $t_{i}$ or at the beginning of interval $(t$, ${ }_{t+1) ;} \sum \lambda_{t, n}=1, \lambda_{t, n} \geq 0$.

$\bar{\lambda}_{t, n}^{a_{i}}$ - fraction of amount of "old" assets in newly invested $i$ asset.

$\bar{\lambda}_{t, n}^{a_{i}}=\lambda_{t, n}^{a_{i}} \times \lambda_{n}$, where $\lambda_{n}$ - growth rate of asset at time $t$.

$a_{t}=i-$ amount of $i$ assets after rebalancing and introducing new at moment $\mathrm{t}$. 
$\mathrm{a}_{\mathrm{t}}^{\mathrm{t}=\mathrm{i}}=\mathrm{a}_{\mathrm{t}}^{\mathrm{i}}\left(1+\lambda_{\mathrm{t}}^{\mathrm{r}}+\bar{\lambda}_{\mathrm{t}, \mathrm{n}}\right)$

$\lambda_{t, n}^{l_{j}}$ - fraction of newly borrowed liabilities in liability category $j$ at time $t_{i}$, or at the beginning of interval $(t$, $t+1)$.

$\bar{\lambda}_{t, n}^{l_{j}}$ - fraction of amount of "old" liabilities in newly borrowed $j$ liability.

$\bar{\lambda}_{t, n}^{l_{j}}=\lambda_{t, n}^{l_{j}} \times \lambda_{t+1}$, where $\lambda_{t+1}$ - growth rate liability at moment $t$.

$\mathrm{P}_{\mathrm{t}+1}^{\mathrm{ai}}-$ index of $i$ asset's price change in year $(t+1)$;

$\mathrm{a}_{\mathrm{t}+1}^{\mathrm{i}}-$ amount of $i$ asset in a result $t+1$ of changes at moment $t$ and price change $\mathrm{a}_{\mathrm{t}+1}^{\mathrm{i}}=\mathrm{a}_{\mathrm{t}}^{\mathrm{t}} \mathrm{P}_{\mathrm{t}+1}^{\mathrm{a}}$.

$\Delta_{\mathrm{t}+1}^{\mathrm{ai}}$ - change in amount of $i$ asset in the year $(t+1)$ because of price and increase in amount at moment $t$.

$\Delta_{t+1}^{\mathrm{ai}}=\mathrm{a}_{\mathrm{t}+1}^{\mathrm{i}}-\mathrm{a}_{\mathrm{t}}^{\mathrm{i}}$.

$\mathrm{a}_{\mathrm{t}+1}^{\mathrm{i}}=\mathrm{a}_{t}^{i}\left(1+\lambda_{t}^{a i}+\bar{\lambda}_{\mathrm{t}, \mathrm{n}}^{\mathrm{ai}}\right) \cdot \mathrm{P}_{\mathrm{t}+1}^{\mathrm{ai}}$.

$\mathrm{a}_{\mathrm{t}+1}^{\mathrm{i}}=\mathrm{a}_{t}^{i}\left(1+\lambda_{t}^{a i}+\bar{\lambda}_{\mathrm{t}, \mathrm{n}}^{\mathrm{ai}}\right) \cdot\left(1+\Delta \mathrm{P}_{\mathrm{t}+1}^{\mathrm{ai}}\right)$, where $\Delta \mathrm{P}_{\mathrm{t}+1}^{\mathrm{ai}}-$ price rate of $i$ asset.

$\Delta_{\mathrm{t}+1, \mathrm{w}}^{\mathrm{ai}}-$ changes in wealth generated by $i$ asset. It consist of changes in amount of asset $i$ because of price changes by adding interest earned by asset $i$ and subs trending some transaction cost if some amount asset was sold.

$\Delta_{\mathrm{t}+1, \mathrm{w}}^{\mathrm{ai}}=\mathrm{a}_{t}^{i}\left(1+\lambda_{t}^{a i}+\bar{\lambda}_{\mathrm{t}, \mathrm{n}}^{\mathrm{ai}}\right) \cdot\left(\Delta P_{t+1}{ }^{a i}+\mathrm{e}_{t+1}{ }^{a i}\right)-C_{t}^{a i}$, where $\Delta P_{t+1}{ }^{a i}$ - price change rate on $\mathrm{i}$ asset at year $(t+1)$;

$\mathrm{e}_{t+1}^{a i}$ - interest rate on $\mathrm{i}$ asset at year $(t+1)$;

$\mathrm{C}_{\mathrm{t}}^{\mathrm{ai}}-$ transaction cost of $\mathrm{i}$ asset sold at time $\mathrm{t}$.

$C_{t}^{a i}=\left\{\begin{array}{ll}a_{t}^{\mathrm{i}}\left(\lambda_{t}^{\text {ai }}+\bar{\lambda}_{t, n}^{\mathrm{ai}}\right) \cdot c_{t}^{\text {ai }} & \text { if } \lambda_{t}^{\text {ai }}+\bar{\lambda}_{\mathrm{t}, \mathrm{n}}^{\mathrm{ai}}<0, \\ 0 & \text { if } \lambda_{\mathrm{t}}^{\mathrm{ai}}+\bar{\lambda}_{\mathrm{t}, \mathrm{n}}^{\mathrm{ai}} \geq 0\end{array}\right.$,

where $C_{t}^{a i}$ - transaction cost rate per unit of asset sold; $1_{t+1}^{j}-$ amount of $j$ liability at time $t+1$;

$1_{\mathrm{t}+1}^{\mathrm{j}}=1_{t}^{j}\left(1+1_{t}^{1 j}+\Delta_{t+1}{ }^{\mathrm{lj}}\right)$.

$\Delta_{t+1}{ }^{1 j}$ - amount of expenditure on $j$ liability in $(t+1)$ year. These expenditures consist of debt service on $j$ liability in $(t+1)$ year plus transaction cost $C_{t}^{1 j}$ of $j$ liabilities sold (changed) at the moment.

$$
\begin{aligned}
& \Delta_{\mathrm{t}+1}^{\mathrm{lj}}=1_{\mathrm{t}}^{\mathrm{j}}\left(1+1_{\mathrm{t}}^{\mathrm{j}}+\bar{\lambda}_{\mathrm{t}, \mathrm{n}}^{\mathrm{lj}}\right) \cdot \mathrm{O}_{\mathrm{t}+1}^{\mathrm{lj}}+\mathrm{C}_{\mathrm{t}+1}^{\mathrm{lj},} \\
& \mathrm{C}_{\mathrm{t}}^{\mathrm{lj}}= \begin{cases}1_{\mathrm{t}}^{\mathrm{j}}\left(\lambda_{\mathrm{t}}^{\mathrm{lj}}+\bar{\lambda}_{\mathrm{t}, \mathrm{n}}^{\mathrm{lj}}\right) \cdot \mathrm{c}_{\mathrm{t}+1}^{\mathrm{lj}} & \text { if } \lambda_{\mathrm{t}}^{\mathrm{jj}}+\bar{\lambda}_{\mathrm{t}, \mathrm{n}}^{-\mathrm{jj}}<0, \\
0 & \text { if } \lambda_{\mathrm{t}}^{\mathrm{lj}}+\bar{\lambda}_{\mathrm{t}, \mathrm{n}}^{-\mathrm{j}} \geq 0,\end{cases}
\end{aligned}
$$

where $\mathrm{O}_{\mathrm{t}+1}^{\mathrm{lj}}$ - payment rate per unit of liability $\mathrm{j}$,

$\mathrm{C}_{\mathrm{t}+1}^{\mathrm{lj}}$ - transaction rate per unit of $\mathrm{j}$ liability sold at $\mathrm{t}$.

$\Delta_{\mathfrak{t}+1}^{\mathrm{net}}-$ increase in total net amount of wealth in year $(t+1)$,

$\Delta_{\mathrm{t}+1}^{\mathrm{net}}=\left(\sum_{\mathrm{i}} \Delta_{\mathrm{t}+1}^{\mathrm{ai}}-\sum_{\mathrm{j}} \Delta_{\mathrm{t}+1}^{\mathrm{lj}}\right)$.

Now lets define inputs and identities of the IALP:

$\mathrm{d}_{\mathrm{t}+1, \mathrm{p}}^{\mathrm{ai}}-$ probability distribution function of $i$ asset price index at the moment $(t+1)$.

$d_{t+1, e}^{\text {ai }}-$ probability distribution function of interest rate on asset $i$ in year $(t+1)$.

$\mathrm{d}_{\mathrm{t}+1, \mathrm{o}}^{\mathrm{lj}}-$ probability distribution function of payment rate on $j$ liability in year $(t+1)$.

$\lambda_{t+1}-$ growth rate of assets and liabilities in year $(t+1)$.

$$
\frac{\sum_{\mathrm{i}} \mathrm{a}_{\mathrm{t}}^{\mathrm{i}}}{\sum_{\mathrm{j}} 1_{\mathrm{t}}^{\mathrm{j}}} \geq 30 \% \text { - the liquidity identity at the beginning }
$$

and at the end of each time interval.

Management mechanisms of IALP:

$U_{t+1}\left(\Delta_{t+1}^{n e t}\{S\}\right)$ utility function defining subject utility from amount of net wealth generated by exploitation of all assets and liabilities.

$\{\mathrm{S}\}-$ symbolize stochasticity of $\Delta_{\mathrm{t}+1}^{\mathrm{net}}$.

Strategy: $\mathrm{U}_{\mathrm{t}+1}^{\Delta_{\mathrm{t}+1} \cdot \mathrm{L}_{\mathrm{t}+1}}\left(\sum_{\mathrm{i}} \Delta_{\mathrm{t}+1, \mathrm{w}}^{\mathrm{ai}}-\sum_{\mathrm{j}} \Delta_{\mathrm{t}+1}^{\mathrm{lj}}\right) \Rightarrow$ optimum.

Optimum means maximum utility from chosen possibility taking into account guarantee of this possibility. 


\subsection{Some remarks on IALP criteria adequacy to subject IALM strategy and possibilities of numerical solution}

It is difficult to deny that one couldn't maximize the utility of any development strategy throughout chosen time horizon $\mathrm{T}$ without knowing how to maximize utility of changes on each time interval (stage).

Utility optimization on each stage was understood as maximization of net wealth growth taking into account riskness (volatility) of the growth. By the way changes in the amount of every asset can include three components:

- Changes in amount of assets because of rebalance between assets;

- Growth because of new acquisition of the assets;

- Changes in the asset value because of price changes.

The same scheme is used for liabilities.

One of paradoxes of stochastic approach to management is that manager or investigator has to realize that forecast is a wide spectrum of possibilities and reality will occur in single realization anyway. As consequence you have some losses because of expectation differs from occurrence or happening. So criteria for decisions ought to react to this objectivity fact seeking to minimize losses because of this noncoincidence. That's why understandings of expectation and guarantee are crucially important in decisionmaking and management under the risk.

Further, if $(i+1)$ year (or $\left(t_{i}, t_{i+1}\right)$ interval) is the year of the investigation then IALP strategy is identical with modern investment portfolio and adequate portfolio maximization problem. That is why the same technique as for mentioned portfolios could be used for analytical and numerical solution of the strategy. Let us demonstrate this concept and techniques on the numerical case.

Informative supply. Financial management whether it is a management of assets or liabilities, or risk management, in some sense it is the management of statistical relations between different variables of the system, or it is management regarding these relations and changing them in the needed way. Actually, the analysis of the system and numerical solution becomes more difficult when the statistical relations between different variables are complicated. We have to admit, that in most of the cases, the amount of information and historical data are not sufficient enough to evaluate all existing statistical relations in the system adequately.
That is why at the given situation we will cover only the analysis of the main statistical relations between egzogenic variables. First, we will consider the existing statistical relations between interest rates earned by different categories of wealth and payments made at different liabilities, norms, which can be shown as correlation matrix $\mathrm{C}(\mathrm{A}, \mathrm{L})$ :

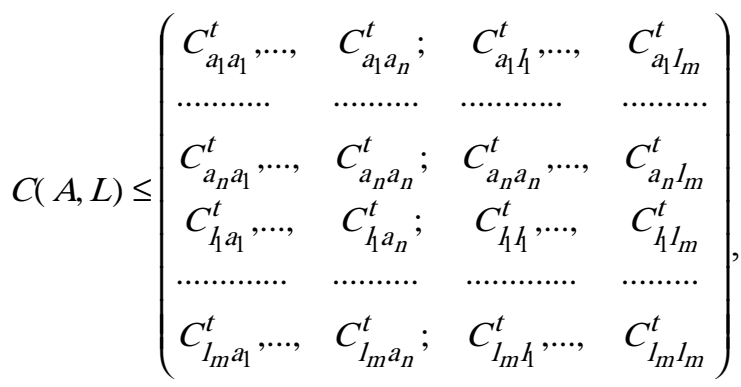

$\mathrm{C}_{\mathrm{a}_{-} \mathrm{i}_{\mathrm{j}}}^{\mathrm{t}}$-is the correlation coefficient in year $t$ between $a-s$ category of wealth interest rate and payments according $j-s$ category of liabilities norms.

We will also consider the existing statistical relations between price increasement indexes of different wealth categories in year $(t+1)$, that can be shown as correlation matrix $\mathrm{C}(\mathrm{P})$ :

$$
\mathrm{C}(\mathrm{P})=\left(\begin{array}{ccc}
C_{p^{a_{1}} p^{a_{2}}} & , \ldots, & C_{p^{a_{1}} p^{a_{n}}} \\
\ldots . . & \ldots . . & \ldots \ldots \\
C_{p^{a_{n}} p^{a_{1}}} & , \ldots, & C_{p^{a_{n}} p^{a_{n}}}
\end{array}\right)
$$

\subsection{The case study}

Suppose that at time $\mathrm{t}$ the commercial bank invested in five groups of assets and five groups of liabilities. The distribution of profitability possibilities of different assets categories and the distribution of probability of liabilities payments norm are shown in the table 1 .

At that time the statistical relations between different variables would look like this:

$$
\mathrm{C}(\mathrm{A} ; \mathrm{L})=\left(\begin{array}{cccccccc}
1 & 0.1 & -0.2 & 0 & 0.3 & 0.18 & 0 & 0 \\
& 1 & 0.15 & 0 & 0.1 & 0.25 & 0.12 & 0 \\
& & 1 & 0 & 0 & 0 & 0.25 & 0 \\
& & & 1 & 0 & 0.2 & 0.1 & 0.3 \\
& & & & 1 & -0.2 & 0 & 0 \\
& & & & & 1 & 0.1 & 0 \\
& & & & & & 1 & 0.05 \\
& & & & & & & 1
\end{array}\right),
$$


Table 1. Assets and Liabilities profitability probability distribution

\begin{tabular}{|c|c|c|c|}
\hline \multicolumn{2}{|c|}{ Assets } & \multicolumn{2}{c|}{ Liabilities } \\
\hline Average & Standard Deviation & Average & Standard Deviation \\
\hline 0.095086 & 0.01304 & -0.045014 & 0.03932 \\
\hline 0.08002 & 0.012016 & -0.040003 & 0.004986 \\
\hline 0.074919 & 0.011012 & -0.033027 & 0.005503 \\
\hline 0.060062 & 0.009984 & -0.030032 & 0.006508 \\
\hline 0.04975 & 0.008995 & -0.0109913 & 0.009483 \\
\hline
\end{tabular}

$$
\mathrm{C}(\mathrm{P})=\left(\begin{array}{cccc}
1 & 0.1 & -0.2 & 0 \\
& 1 & -0.32 & 0.1 \\
& & 1 & 0 \\
& & & 1
\end{array}\right) .
$$

Strategic goals for the bank on given stage are: to meet Central bank requirements of minimum of liquidity ratio $-30 \%$ (short term asset - short term liabilities ratio) by taking new loans on already existing liabilities and parallel rebalance existing structure of assets and liabilities in order to optimize the growth of net wealth in time period $[t, t+1)$.

Analytically the problem could be formulated in such a manner: define fractions of newly invested assets in $i$ category of asset $\bar{\lambda}_{t, n}^{a_{i}}$ and growth index of $i$ asset in result of rebalancing existing up to the time $t$ assets $I_{t+1}^{a_{i}}$ and fractions of newly borrowed liabilities in liability $j$ category $\bar{\lambda}_{t, n}^{l_{j}}$ and growth index of $j$ liability in result of rebalancing existing up to the time liabilities $-I_{t+1}^{l_{j}}(i=1,2,3,4 ; j=1,2,3,40)$ in order to optimize subject utility from growth net wealth.

Of remember that interest rate on $I$ asset $-e_{t+1}^{a_{i}}$, payment rate per unit of liability $j-o_{t+1}^{l_{j}}$ are stochastical variables and growth indexes of $i$ asset $I_{t+1}^{a_{i}}$ and $j$ liability $-I_{t+1}^{l_{j}}$ in result of rebalancing existing up to time $I$ assets and liabilities are dependent on stochastical variables and event then the problem of optimisation is evidently the identical case of IALP and could be solved by the same techniques as classical (modern) investment portfolio or as adequate to the stochasticity of assets and liabilities portfolio (Rutkauskas A. V., 2000).

\subsection{Interpretation of obtained results}

Using imitation technologies (Rutkauskas A.V., 2000) we can define wealth increasement possibilities of year $(t+1)$ shown in graphic pictures.

Fig 3a shows all net assets increasement possibilities of all categories of wealth, which are obtained while using the principle of portfolio formation. If we consider that Markowitz average-standard deviation portfolio is a standard, then we have the set of the analogues of quarties: 0,$05 ; 0,25 ; 0,5 ; 0,75 ; 0,95$ standard deviation portfolios (the conception of analogue will be explained better in the last paragraph). It is more difficult to interpret payments bound with expected possibility of liabilities service. Fig 3 b shows portfolio analogues of payments possibilities for different levels of analogues. There is no doubt that analysts will be interested only in the points lying on the edge points of cost possible values. In case of Markowitz portfolio, this will be the envelopment curve. Fig $3 \mathrm{c}$ gives information about net assets increasement possibilities in year $(t+1)$. Fig $3 \mathrm{c}$ shows analogues of adequate investment portfolio for 0,$001 ; 0,02 ; 0,04 ; \ldots, 0,98$ and 0,995 level of quintiles.

Fig 3d shows the effective lines of analogues of assets and liabilities portfolios that serve as isoguarantees in this case. We can see isoguarantee of minimum $(0,001)$, isoguarantee of maximum $(0,995)$ and isoguarantees of all deciles in Fig $3 d$. Note that values of isoguarantees are almost entirely increasing as the dispersion increases so we have some remarks to make.

First, isoguarantee gives us information that with your chosen guaranty the net assets increasement will be no smaller than the value of isoguarantee in a given level of risk, if you are not choosing from the set of possibilities, but from the effectives lines only.

Second, to better understand net assets increasement possibilities we have to use the spherical picture of survival functions family (Fig 3e), where we can find information about net assets possibilities, which are chosen, below the level of isoguarantee. This can explain why the higher level of net assets, when guaranty is the same, not necessary means higher expected utility. Despite that, while trying to find the best structure of assets and liabilities, there were limited variation possibilities for the variables causing them, because in other way we should also change $c_{t}^{a_{i}}$ coefficients also.

Fig 3e gives good and relevant information about net assets increasement possibilities. We have the levels of possible risk on abscissa axis, assets increasement possibilities on coordinate axis, and the levels of 


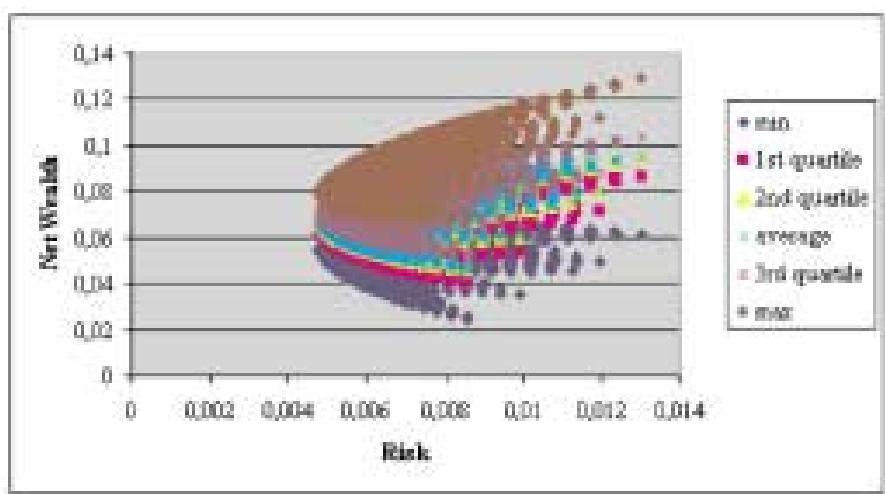

Fig $3 a$

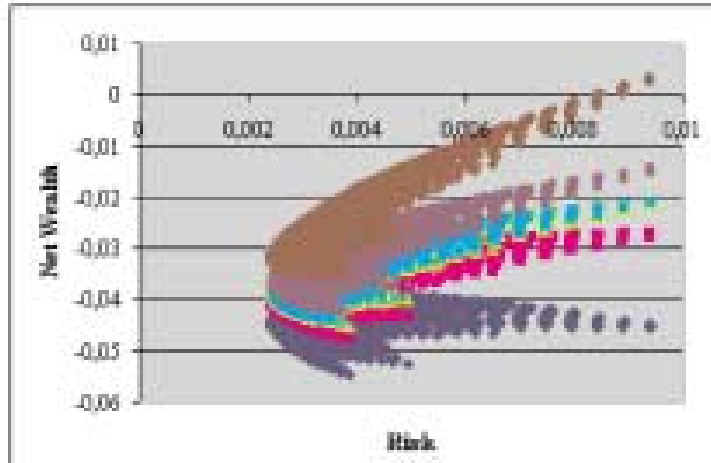

Fig 3b

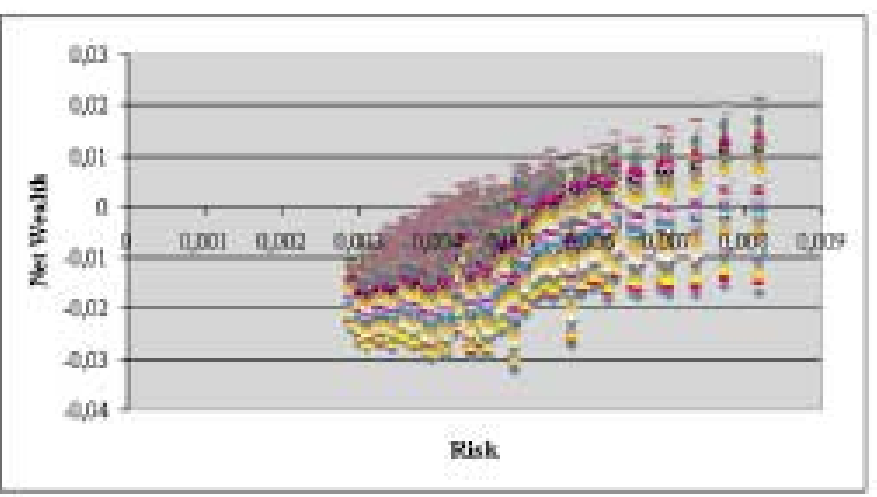

Fig 3c
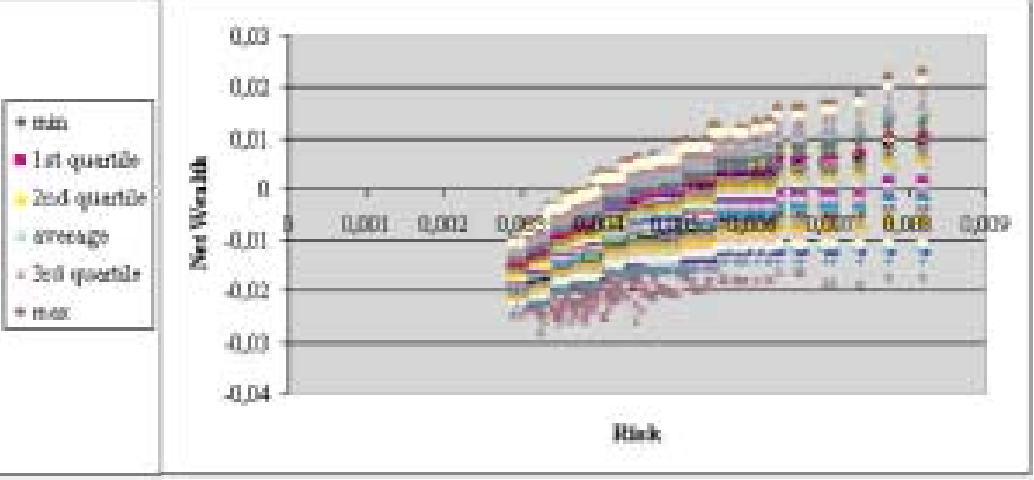

Fig $3 d$

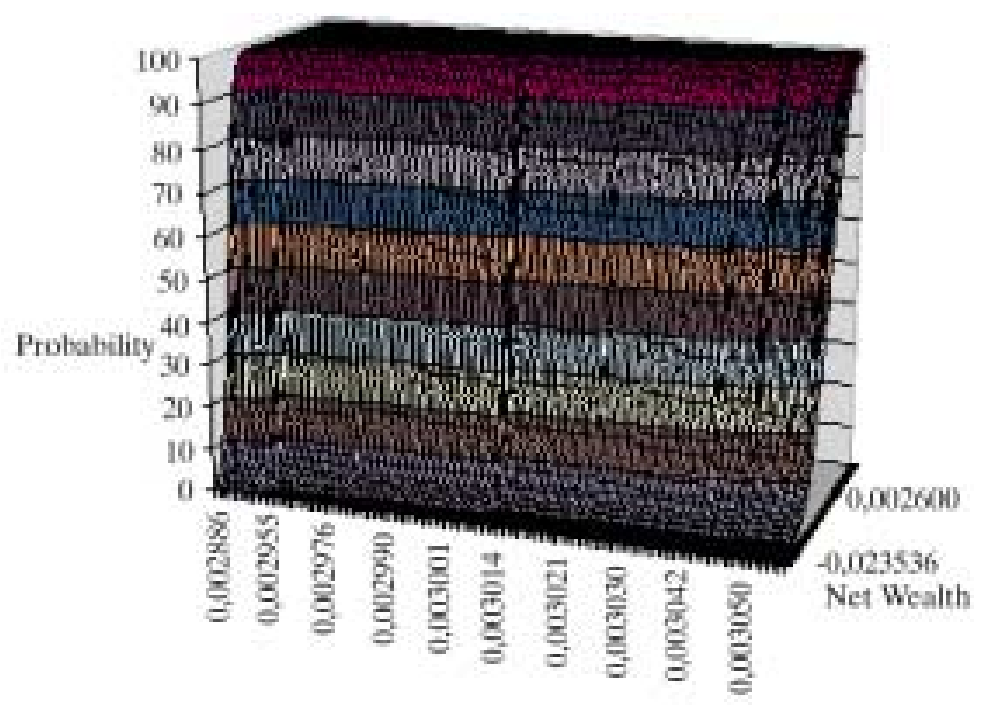

Fig 3e

Fig 3. Possibility sets of asset and liability portfolio analogues: $3 \mathrm{a}$ - assets portfolio analogues of standard deviation 0,005 ; 0,$25 ; 0,5 ; 0,75$ and 0,995 levels of quintiles; $3 b$ - liabilities portfolio analogues of standard deviation 0,$005 ; 0,25 ; 0,5 ; 0,75$ and 0,995 levels of quintiles; $3 c$ - assets and liabilities portfolio analogues of standard deviation 0,$005 ; 0,25 ; 0,5 ; 0,75$ and 0,995 levels of quintiles; $3 \mathrm{~d}$ - isoguarantees of corresponding level of assets and liabilities portfolio analogue; $3 \mathrm{e}-$ survival functions family of portfolio analogues

guaranties on Z-axis. It is always easy to find a point or set of points that maximize the utility of a subject if the utility function is known. And finally, Fig 3e shows the projection of the effective zone in the abscissa-coordinate system that visually gives information about utility dynamics possibilities in changing risk levels.

\subsection{Short comment on solution method}

While solving the given problem, the idea of portfolio analogue has been used. In order to explain the essence of portfolio analogue we should remember the concept of investment portfolio: $\mathrm{n}$ investments $\mathrm{a}_{i}(i=$ $1,2, \ldots, n)$ portfolio is a set $\left\{\mathrm{w}_{\mathrm{i}}, \mathrm{i}=\overline{1, \mathrm{n}}\right\}$ of any 
structural indicators $\mathrm{w}_{i}\left(r=1,2, \ldots, n ; 0 \leq \mathrm{w}_{i} 1\right.$, $\left.\sum_{r=1}^{n} w_{i}=1\right) . W=\sum_{r=1}^{n} w_{i} * a_{i}$ is called a value of portfolio. So we are analyzing the set of all possible portfolios and the set of all possible values of portfolios. Because $a_{i}$ is random variable so $\mathrm{w}$ is also a random variable. Markowitz or modern portfolio refers to analysis of interaction of average and standard deviation of these random measures and is based on using the characteristics of. Effective line consists of points, obtained when choosing maximum from all possible portfolio values for each possible standard deviation value. Effective line is one of the best instruments for multicriteria analysis.

Not only average values are used in the case of adequate portfolio, but full distribution of portfolio values possibilities, or using the effective line all possible quintiles are being analyzed (e.g. quartiles, deciles, percentiles or their combinations). As a result, so-called effective zone is being formed instead of effective line (in case of Markowitz portfolio).

Portfolio analogue, solving ITIVS and other sophisticated problems, is a set $\left\{x_{i}^{p} ; i=\overline{1, n}\right\}$ of any ITIVS value of variables $x_{i}(I=1,2, \ldots, n$; $\left.a_{i} \leq x_{i} \leq b_{i}\right)$. The value of portfolio analogue is a value $\mathrm{F}$ of utility function, when $\mathrm{x}_{\mathrm{i}}=\mathrm{x}_{\mathrm{i}}^{\mathrm{p}}$ :

$$
F=f\left(x_{1}^{p}, x_{2}^{p}, \ldots, x_{n}^{p}\right) .
$$

In the case of adequate portfolio it is a function from the distribution of egzogenic variables possibilities. The example is survival functions family.

Having geometric view of survival functions family, i.e. the set of possible solutions, which is called restriction set in the mathematical forecasting problems, it becomes clear how to find a point or a set of points in the set of possible solutions when knowing the utility function (Fig 3e).

\section{Conclusions}

- Integrated asset and liability portfolio management becomes the main element of strong liquidity management at a bank of any size or scope of operations. The information systems and analysis needed to implement the approach, however, would typically absorb fewer resources and be much less complex at a smaller bank or one that is active in fewer markets than those at large, complex banks.
- Development of management theory and practices encounters two fully perceptible and mutually unobjectionable aspects with the intersection points very difficult to reveal. One of them is that the future of the process of many self-regulating and management objects cannot be defined determinately. The second is that in reality the development of the process will choose only one possibility. The adjusting process of these two aspects in portfolio management is burden by the fact that desirable states of portfolio results are defined by two oneaspect indicators: profitability and reliability. Consequently decision-making algorithms should encounter commensurable of these indicators.

- It is needed to consider every state of all kinds of quintile - risk portfolios for the creation of effective portfolio management algorithm. Its reliability should to be the inseparable characteristic of these states. Isoguarantees should serve for investor as easy understandable component of his (hers, its) decision-making criterion. Its capability to help for arrangement isoguaranted states according level of another indicator is of incredible value in decisionmaking. Under quite general assumption isoguarantee could lead to final decision making. Thought sense of isoguarantee used in portfolio decision coincides with the sense of term of isoquintile used in statistics and definition of its analytical expression usually is quite difficult and needs to use of imitative technologies.

- Integral asset and liability management becomes an independent perspective of financial process management, widely used in different financial institutions as well as in personal finances. Integral asset and liability portfolio, offered in the article, should become compound element of asset and liability management perspective, helping to answer questions where and how much to borrow, where and how much to invest, and also helping to join forecasting and planning, and risk management systems together.

\section{References}

Baston, R. G. (1989). Financial Planning using Goal Programming. Long Range Planning, Vol. 22 (17), p. 112120.

Berger, A. J.; Mulvey, John M. (2001). The Home Account Advisor $^{\mathrm{TM}}$, Asset and Liability Management for Individual Investors. In: Ziemba W. T., Mulvey J. M. (Eds.), Worldwide Asset and Liability Modeling. Publication of the Newton Institute. Cambridge University Press, p. 634-665. 
Booth, G. G. (1972). Programming Bank Portfolios under Uncertainty: An Extension. Journal of Bank Research, 2, p. $28-40$.

Booth, G. G.; Bessler, W. and Foote, W. G. (1989). Managing interest-rate risk in banking institutions. European Journal of Operations Research, Vol 4 (3), p. 673-686.

Bradley, S. P. and Crane, D.B. (1972). A Dynamic Model for Bond Portfolio Management. Management Science, 19, p. 139-151.

Brodt, A. I. (1978). Dynamic Balance Sheet Management Model for a Canadian Chartered Bank. Journal of Banking and Finance, Vol 2(3), p. 221-241.

Carino, D. R.; Kent, T.; Myers, D. H.; Stacy, C.; Sylvanus, M.; Turner, A.; Watanabe, K.; Ziemba, W. T. (2001). The Russell-Yasuda Kasai model: an asset/liability model for a Japanese insurance company using multistage stochastic programming. In: Ziemba W. T., Mulvey J. M. (Eds.), Worldwide Asset and Liability Modeling. Publication of the Newton Institute. Cambridge University Press, p. 609-633.

Carino, D. R.; Kent, T.; Muyers, D. H.; Stacy, C.; Sylvanus, M.; Turner, A. L.;Watanabe, K. and Ziemba, W. T. (1994). The Russell-Yasuda Kasai Model: An Asset/Liability Model for a Japanese Insurance Company Using Multistage Stochastic Programming, Interfaces, Vol 24, p. 29-49.

Chambers, D. and Charnes, A. (1961). Inter-Temporal Analysis and Optimization of Bank Portfolios. Management Science, Vol 7, p. 393-410.

Charnes, A. and Littlechild, S. C. (1968). Intertemporal Bank Asset Choice with Stochastic Dependence. Systems Research Memorandum no.188, The Technological Institute, Nortwestern University, Evanston, Illinois.

Charnes, A. and Thore, S. (1966). Planning for Liquidity in Financial Institution: The Chance Constrained Method. Journal of Finance, 21/4, p. 649-674.

Cohen, K. J. and Hammer, F. S. (1967). Linear Programming and Optimal Bank Asset Management Decisions. Journal of Finance, Vol 22, p. 42-61.

Cohen, K. J. and Thore, S. (1970). Programming Bank Portfolios under Uncertainty. Journal of Bank Research, 2, p. $28-40$.

Crane, B. (1971). A Stochastic Programming Model for Commercial Bank Bond Portfolio Management. Journal of Financial Quantitative Analysis, 6, p. 955-976.

Dert, C. (2001). A dynamic model for asset liability management for defined benefit pension funds. In: Ziemba W. T., Mulvey J. M. (Eds.), Worldwide Asset and Liability Modeling. Publication of the Newton Institute. Cambridge University Press, p. 501-536.

Dert, C. (1995). A dynamic model for asset/ liability management for defined benefit pension funds, Worldwide Asset and Liability Modeling.

Eatman, L. and Sealey, Jr. (1979). A Multi-objective Linear Programming Model for Commercial bank Balance Sheet
Management. Journal of Bank Research, Vol 9, p. 227 236.

Eppen, G. D. and Fama, E. F. (1971). Three Asset Cash Balance and Dynamic Portfolio Problems. Management Science, 17, p. 311-319.

Giokas, D. and Vassiloglou, M. (1991). A Goal Programming Model for Bank Assets and Liabilities. European Journal of Operations Research, Vol 50, p. 48-60.

Holmer, M. (2001). Integrated asset-liability management: an implementation case study. In: Ziemba W. T., Mulvey J. M. (Eds.), Worldwide Asset and Liability Modeling. Publication of the Newton Institute. Cambridge University Press, p. 581-608.

Holmer, M. (1999). Integrated asset/ liability management: an implementation case study. Worldwide Asset and Liability Modeling.

Kallberg, J. G.; White, R. W. and Ziemba, W. T. (1982). Short Term Financial Planning under Uncertainty. Management Science, 28, p. 670-682.

Kosmidou, K. and Zopounidis, C. (2001). Bank Asset Liability Management Techniques: An Overview. C. Zopounidis, P. M. Pardalos, G. Baourakis (Eds.), Fuzzy Set Systems in Management and Economy, World Scientific Publishers, p. 255-268.

Kosmidou, K. and Zopounidis, C. (2004). Goal Programming techniques for bank asset liability management, Kluwer Academic Publishers.

Kouwenberg R. (2001). Scenario generation and stochastic programming models for asset liability management. European Journal of Operational Research, Vol 134, Issue 2, 16 October 2001, p. 279-292.

Kusy, I. M. and Ziemba, T. W. (1986). A Bank Asset and Liability Management model. Operations Research, Vol 34, No 3, p. 356-376.

Kvanli, A. H. (1980). Financial planning using goal programming. OMEGA. The International Journal of Management Science, Vol 8 (2), p. 207-218.

Lee, S. M. and Chesser, D. L. (1980). Goal programming for portfolio selection. Journal of Portfolio Management, Vol 6, p. 22-26.

Lee, S. M. and Lerro, A. J. (1973). Optimizing the portfolio selection for mutual funds. Journal of Finance, Vol 28, p. 1086-1101.

Lifson, K. A. and Blackman, B. R. (1973). Simulation and Optimization Models for Asset Deployment and Funds Sources Balancing Profit Liquidity and Growth. Journal of Bank Research, Vol 4(3), p. 239-255.

Markowitz, H. M. 1990. .Mean Variance Analysis in Portfolio Choice and Capital Markets, Basil, Blackwell.

Markowitz, H. M. (1959). Portofolio Selection, Efficient Diversification of Investments. John Wiley and Sons, New York.

Merton, R. C. (2001). Optimal investment strategies for university endowment funds. In: Ziemba W. T., Mulvey J. M. (Eds.), Worldwide Asset and Liability Modeling. 
Publication of the Newton Institute. Cambridge University Press, p. 371-396.

Mulvey, J.M. and Vladimirou, H. (1992). Stochastic Network Programming for Financial Planning Problems. Management Science, Vol 38, p. 1642-1663.

Mulvey, J. M., and Ziemba, W. T. (1998). Asset and liability management systems for long-term investors: discussion of the issues, in Worldwide Asset and Liability Modelling, (W. Ziemba and J. Mulvey, eds). Cambridge University Press, United Kingdom, p. 3-38.

Oguzcoy, C. B.; Güven, S. (1997). Bank asset and liability management under uncertainty. European Journal of Operational Research, Vol 102, Issue 3, 1 November 1997, p. 575-600.

Pogue, G. A. and Bussard, R. N. (1972). A Linear Programming Model for Short Term Financial Planning under Uncertainty. Sloan Management Review, 13, p. 69-98.

Pyle, D. H. (1971). On the Theory of Financial Intermediation. Journal of Finance, Vol 26, p. 737-746.

Robertson, M. (1972). A Bank Asset Management Model. S. Eilon and T. R. Fowkes (eds.). Applications of Management Science in Banking and Finance. Gower Press. Epping. Essex, p. 149-158.

Rutkauskas, A. V. (2000). Formation of Adequate Investment Portfolio for Stochastically Possibilities. Property Management, Vol 4, No 2. Vilnius: Technika, p. 100-116.

Rutkauskas, A. V.; Stankeviciene, J. (2003). Formation of an Investment Portfolio Adequate for Stochasticity of Profit Possibilities. Journal of Business Economics and Management, ISSN 1611-1699, Vol IV, No 1, p. 3-12.

Seshadri, S.;Khanna, Al; Harche, F. and Wyle, R. (1999). A method for strategic asset liability management with an application to the federal home loan bank of New York. Operations Research, Vol 47 (3), p. 345-360.

Sharma, J. K.; Sharma, D. K. and Adeyeye, J. O. (1995). Optimal portfolio selection: A goal programming approach. Indian Journal of Finance and Research, Vol 7 (2), p. 67-76.

Spronk, J.; Hallerbach, W. (1997). Financial modelling: Where to go? With an illustration for portfolio management. European Journal of Operational Research, Vol 99, Issue 1, 16 May 1997, p. 113-125.

Wolf, C. R. (1969). A Model for selecting Commercial Bank Government Security Portfolios. Rev. Econ. Stat., Vol 1, p. 40-52.

Ziemba, W. T., and Mulvey, J. M. (1998). Worldwide Asset and Liability Modeling. Cambridge University Press, United Kingdom. 